\title{
Astaxanthin and risk of cardiovascular diseases: a meta-analysis of epidemiological evidence
}

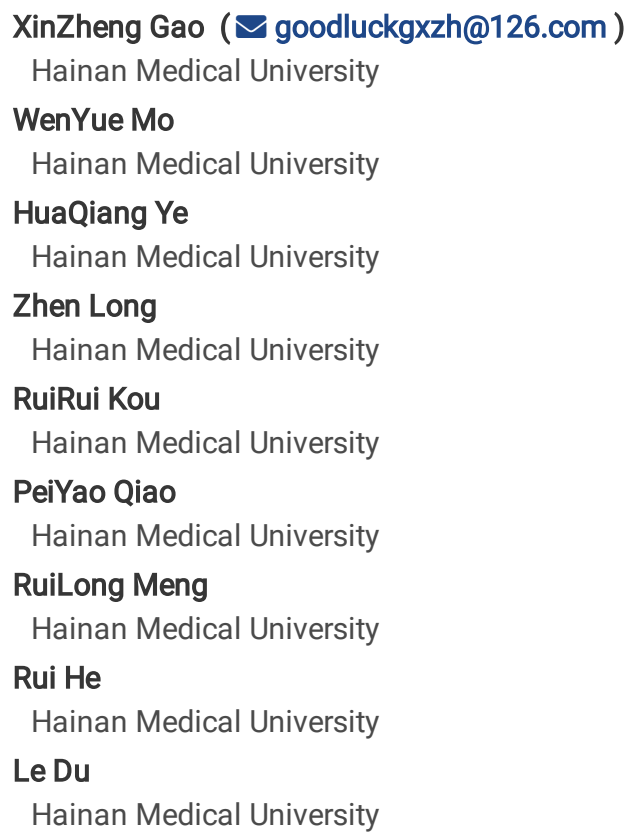

\section{Research Article}

Keywords: Astaxanthin, Lipids, Glucose, Pressure, BMI, Cardiovascular system

Posted Date: February 16th, 2022

DOI: https://doi.org/10.21203/rs.3.rs-1357277/v1

License: (c) (i) This work is licensed under a Creative Commons Attribution 4.0 International License. Read Full License 


\section{Abstract}

Background: The purpose of this study was to analyze and evaluate the effect of astaxanthin on clinical indicators related to cardiovascular disease.

Methods: Fives databases include PUBMED, CNKI, WEIPU, WAN FANG and ClinicalTrials were searched up to January 31, 2022, and the randomeffects model was used to calculate the summary risk. A total of 14 epidemiological studies were included in this meta-analysis.

Results: The overall study showed no significant dose-response association of astaxanthin (AST) with diastolic blood pressure, DBP (weighted mean difference, WND:-0.186, 95\%confidence interval, Cl:-0.374 to 0.002, $P=0.052$ ) and body mass index, BMI (WND:0.095, 95\%Cl: -0.164 to $0.354, P=0.473)$. However, the results revealed that astaxanthin can significantly reduce the concentrations of total cholesterol (WND:-0.310, $95 \%$ Cl:-0.541 to $-0.168, P=0.000)$, the concentrations of low-density lipoprotein cholesterol, LDL-C (WND: $-0.207,95 \%$ Cl: -0.396 to $-0.019, P=0.031$ ), the concentrations of triglyceride (WND:-0.603, 95\% Cl:- 1.028 to $-0.179, P=0.005)$, the concentrations of glucose (WND: $-0.353,95 \% \mathrm{Cl}-0.596$ to $-0.110, P=0.004)$ and systolic blood pressure, SBP(WND:-0.258, 95\% Cl:-0.495 to $-0.021, P=0.033$ ). Moreover, astaxanthin could increase the concentrations of high-density lipoprotein cholesterol, HDL-C (WND: $-0.294,95 \% \mathrm{Cl}:-0.515$ to $-0.072, P=0.009)$.

Conclusions: This meta-analysis indicates that astaxanthin has a protection role on the cardiovascular system. Further studies need to be conducted to verify the findings.

\section{Background}

Astaxanthin belongs to a xanthophyll carotenoid, and it was known as the miracle of red(3,3'-dihydroxy- $\beta$, $\beta$-carotene-4,4'-dione). There are five sources of astaxanthin, including yeast, algae, crops, crustaceans, bacteria and protozoans [1]. Astaxanthin was firstly discovered in lobsters in 1938 and was initially used for the only pigmentation in aquaculture [2]. Astaxanthin has unique chemical properties. It is composed of a series of conjugated double bonds, violet ketone ring, hydroxyl $(\mathrm{OH})$ and keto $(\mathrm{C}=0)$. These unique structures can neutralize and scavenge free radicals inside and outside the cell membrane. Astaxanthin has both hydrophilic and hydrophobic groups, which can cross the whole-cell membrane to protect the inside and outside the cell. The molecular structure of astaxanthin ensures the unparalleled penetration of astaxanthin, which penetrates the blood-brain barrier, skins and all organs [2-4]. Astaxanthin act as a safeguard against oxidative and inflammatory damage by various mechanisms. Astaxanthin promotes the dissociation and nuclear translocation of nuclear erythroid 2-related factor, Nrf2 through activating the signaling pathways of PI3K/Akt and extracellular signal-regulated kinase, ERK, which contributes to increased expression of Nrf2regulated enzymes that resist oxidative stress. Astaxanthin negatively regulates the Sp1/NR1 signaling pathway, alleviating the production of intracellular reactive oxygen species, ROS and oxidative stress. In addition, through restraining IKB-a degradation and NF-KB nuclear translocation, astaxanthin inhibits the expression of inflammatory molecules interleukin-6 (IL-6), cell adhesion molecules-1 (ICAM-1), and monocyte chemoattractant protein-1 (MCP-1). Astaxanthin also suppresses the nuclear expression of NF-KB and reduces downstream production of pro-inflammatory cytokines by restoring physiological levels of SHP-1 [23,24,33,34]. Thus, astaxanthin plays a vital role in antiinflammation and anti-oxidation. Astaxanthin can resist diseases caused by oxidative stress such as metabolic syndromes, neurodegenerative diseases, cardiovascular diseases, inflammatory diseases and age-related diseases.

Cardiovascular disease is the leading cause of death in the world. At present, the research that astaxanthin affects cardiovascular disease has been increasing [5-8]. However, there are some controversies about the conclusions. Since meta-analysis can systematically evaluate and summarize the results of multiple studies on the same subject, a meta-analysis was presented to assess the efficacy of astaxanthin on cardiovascular diseases in epidemiological studies. This meta-analysis of epidemiological studies powerful revealed that significant reductions in cardiovascular system disease were associated with astaxanthin intake. The astaxanthin remarkably reduces blood lipid concentration, plasma glucose concentration and blood pressure.

\section{Methods}

\section{Search strategy}

Following the Preferred Reporting Items for Systematic Reviews and Meta-analysis (PRISMA) statements checklist, PUBMED, CNKI, WEIPU, WANFANG and ClinicalTrials were searched from inception to January 31, 2022. Furthermore, the online search of published literatures were conducted through PubMed using the MeSH (Medical Subject Headings) term and additional grey literature. The search terms keywords were as follows: (astaxanthin or AST or haematococcus pluvialis) and (randomized controlled trial or randomized) and (cholesterol or total cholesterol) and (triglyceride) and (HDL-cholesterol or HDL or high-density lipoprotein) and (LDL-cholesterol or LDL or low-density lipoprotein) and (cardiovascular system or cardiovascular or angiography or heart and blood vessels) and (blood glucose or plasma glucose or FBG or hyperglycemia or hyperglycaemia or hyperglycemic) and (hyperlipidemia or hyperlipidemic or dyslipidemia) and (blood pressure or diastolic 
pressure or diastolic blood pressure or systolic pressure or systolic blood pressure) and (body mass index or BMI). There are no restrictions on the type of language. This study was limited to human studies, and the retrieved articles were screened by hand.

\section{Study selection}

The included articles had to meet the following inclusion criteria: (1) Meeting the criteria of prospective cohort studies or case-control studies; (2) The effect of astaxanthin on the index related to cardiovascular disease was evaluated (i.e., total cholesterol, triglycerides, high-density lipoprotein cholesterol, low-density lipoprotein cholesterol, diastolic pressure, systolic pressure, plasma glucose); (3) Astaxanthin was given in the experimental group, the control group used placebo control or blank control; (4) The limiting factor was a pure astaxanthin preparation with a precise dose, or was the dose that can be calculated based on data available in the literature.

The exclusion criteria were as follows: (1) repetitive articles or just titles, abstracts; (2) systematic review, meta-analysis, case reports; (3) letters, and conference data; (4) animal or cell experiments; (5) no control group.

\section{Data extraction}

Information was extracted independently by two investigators. The disagreements were adjudicated by the third investigator. Each eligible study was reviewed and extracted as follows:1) the first author; 2) the year of publication; 3) country; 4) age; 5) sex; 6) the daily dosage of the astaxanthin groups and control groups; 7) the number of participants in the astaxanthin groups and control groups; 8 ) the means and standard deviations of total cholesterol concentration, HDL-C, LDL-C, triglyceride concentration, plasma glucose concentration, diastolic pressure, systolic pressure and body mass index (BMI); 9) the follow-up time for cohort studies.

\section{Quality assessment}

Using the Cochrane Collaboration tool to assess the quality of each study. The evaluation content mainly included: selection bias, performance bias, detection bias, attrition bias, reporting bias and other biases. The low risk of bias, high risk of bias and unknown risk of bias were evaluated. The evaluative results were divided into three levels, including low risk, high risk and unclear. In the overall analysis of multiple studies, the majority of the information from low risk of preference was called "low risk of bias"; most of the information from unknown risk of preference was considered as "unclear risk of bias"; the proportion of data from studies which are high risk of preference and sufficiently affect the interpretation of results was known as "High risk of bias". The quality evaluation was executed independently by two authors, and the different opinions were decided by a third author.

\section{Statistical analysis}

All statistical analyses were conducted by the Comprehensive Meta-Analysis Software, version v. 2.0. As a more conservative estimate, the random-effects model was used to calculate the summary risk. Forest plots described WMD and $95 \% \mathrm{Cl}$ for the effect of astaxanthin in detail. Heterogeneity among studies was estimated through calculating the Q-statistic and $\mathrm{I}^{2}$ value. The change of $\mathrm{I}^{2}$ value is due to heterogeneity. The Q-statistic and $\mathrm{I}^{2}$ value describes the percent of different studies due to heterogeneity rather than chance, of which $0 \%$ declares no observed heterogeneity, with $25 \%$ regarded as low, $50 \%$ as moderate, and $75 \%$ as high [9]. If a $p$-value $<0.05$ indicated the presence of significant heterogeneity, sensitivity analysis is needed for further exploration. The sensitivity analysis evaluated whether the combined estimates could have been a substantial impact by a single study, each study was excluded one by one, and the investigation based on the remaining studies through forest plot. Publication bias was explored through funnel plots in the studies which were selected for research, and the methods of Begg's test and Egger's test evaluated further whether publication bias exists (there was no publication bias if the funnel plot was symmetric), provided a $p$-value $<0.05$ indicated the presence of potential publication bias. The means of trim and fill analysis was used to examine the effects of possibly missing studies. A correlation coefficient (R) was assumed as 0.5 [10].

\section{Results}

\section{Characteristics of Eligible Studies}

\section{Literature search}

A total of 8964 publications was collected from the four databases, of which 1058 were reviewed through titles and, or abstracts, 958 articles were excluded because they were titles, abstracts, meta-analyses, case reports, systematic reviews and irrelevant articles. $100 f u l l-t e x t$ articles 
were screened, and 36 articles fulfilled the inclusion criteria. Finally, 13 studies were selected for the meta-analysis, and the reasons for excluding 23 studies from the remaining articles were as follows: 19 studies combined astaxanthin with other drugs, 4 studies hadn't control group. The flow diagram is shown in Figure 1.

\section{Study characteristics}

The Study characteristics show in Table 1. They were all prospective cohort studies. Eight studies were conducted in Asia (Korea, $\mathrm{n}=1$; Japan, $\mathrm{n}=5$; Iran, $\mathrm{n}=1$; China, $\mathrm{n}=4$ ), one study was conducted in Europe (Finland, $\mathrm{n}=1$ ), and one study was conducted in America (Canada, $\mathrm{n}=1$ ). The other information of the included studies was age range, sex, astaxanthin dose, placebo dose and follow-up period.

\section{Quality assessment}

The results of the quality assessment with Cochrane criteria are summarized in Table 3 . The quality about the included studies was varied, 46 items of information were low-risk bias, and 43 items of information were unclear bias risk. Only 1 item was high-risk bias, but it didn't affect our findings. Therefore, the included articles were high-quality studies.

\section{Blood lipid}

Thirteen studies on the relationship between astaxanthin and the concentration of cholesterol were shown in Figure 2.1. The astaxanthin could remarkably recover the plasma concentration of total cholesterol (WND: $-0.310,95 \% \mathrm{Cl}:-0.541$ to $-0.168, P=0.000, \mathrm{Z}=-4.294$ ); HDL-C (WND: $-0.294,95 \% \mathrm{Cl}:-0515$ to $-0.072, P=0.009, \mathrm{Z}=2.594)$; LDL-C (WND: $-0.207,95 \% \mathrm{Cl}$ : -0.396 to $-0.019, P=0.031, Z=-2.153$ ); triglyceride (WND:-0.603, $95 \% \mathrm{Cl}:-1.028$ to $-0.179, P=0.005, \mathrm{Z}=-2.787)$. The analyses for total cholesterol, HDL-C and LDL-C showed in Table 2 that the heterogeneity was not statistically significant (Total cholesterol: $I^{2}=0.000, Q=13.598, P=0.755 ; \mathrm{HDL}-\mathrm{C}: \mathrm{I}^{2}=37.794, \mathrm{Q}=27.329, P=0.053:$ LDL-C: ${ }^{2}=0.000, \mathrm{Q}=$ 3.210, $P=0.999$ ). However, there were publication biases of total cholesterol, HDL-C and LDL-C in Table 2. (Total cholesterol: $p_{\text {Begg }}=0.008$, $p_{\text {Egger }}=0.024 ; \mathrm{HDL}-\mathrm{C}: p_{\text {Begg }}=0.014, p_{\text {Egger }}=0.083$ : LDL-C: $\left.p_{\text {Begg }}=0.002, p_{\text {Egger }}=0.008\right)$. According to the trim and fill analysis, these studies were filled in the right of the mean to make the funnel symmetrical, and the adjusted estimated effect based on the random-effects model, the result emerged the adjusted values was consistent with the observed values in Figure 5. (Total cholesterol: lower limit -0.451 to upper limit - 0.168 , $\mathrm{Q}=13.598$; HDL-C: lower limit 0.07178 to upper limit 0.51532, Q=27.329; LDL-C: lower limit -0.39587 to upper limit 0.01854, Q=3.210). In analyses for Triglyceride, no publication bias was detected (Triglyceride: $p_{\mathrm{Begg}}=0.06250, p_{\mathrm{Egger}}=0.20944$ ). There was significant heterogeneity (Triglyceride: $\mathrm{I}^{2}=84.083, \mathrm{Q}=87.956, P=0.000$ ). They were shown in Table 2 . To determine whether the comprehensive assessments would have been markedly affected by single research, the sensitivity analysis was conducted. The results in Figure 3 showed that substantial heterogeneity was not observed in this analysis (all of $P$-Value $>0.00$ ).

\section{Plasma glucose}

Four studies focused on the effect of astaxanthin on plasma glucose concentrations, as shown in Figure 2.2. The results suggested that astaxanthin significantly reduced the blood glucose of patients (WND: $-0.353,95 \% \mathrm{Cl}$ : -0.596 to $-0.110, P=0.004, Z=-2.848$ ). The meta-analysis in Table 2 suggested that the heterogeneity was not statistically significant $\left(I^{2}=20.991, Q=6.328, P=0.276\right)$. These result sindicated evidence of no publication bias $\left(p_{\text {Begg }}=0.42549, p_{\text {Egger }}=0.24654\right)$.

\section{Blood pressure}

Six studies investigated the role of astaxanthin in controlling blood pressure, as shown in Figure 2.3. The results didn't show the potential role of astaxanthin in DBP (WND: $-0.186,95 \% \mathrm{Cl}$ : -0.374 to $0.002, P=0.052, \mathrm{Z}=-1.943$ ), while astaxanthin was significant for reducing SBP (WND: $-0.236,95 \% \mathrm{Cl}:-0.425$ to $-0.048, P=0.014, \mathrm{Z}=-2.460)$. No significant publication bias was observed in this analysis (DBP: $p_{\mathrm{Begg}}=0.105, p_{\mathrm{Egger}}=$ 0.103; SBP: $\left.p_{\text {Begg }}=0.266, p_{\text {Egger }}=0.216\right)$. The heterogeneity wasn't significant in this study (DBP: $I^{2}=0.000, Q=1.235, p=0.996 ;$ SBP: $I^{2}=0.000$, $\mathrm{Q}=3.636, p=0.888)$. These were shown in Table 2 .

\section{BMI}

As shown in Figure 2.4, five studies evaluated the association between astaxanthin and body mass index. The results indicated the null effect of astaxanthin on BMI (WND: $0.095,95 \% \mathrm{Cl}:-0.164$ to $0.354, p=0.473)$. Heterogeneity was not found in the analysis $\left(I^{2}=0.000, Q=0.592, P=\right.$ 
0.999). However, the publication bias existed in Table $2\left(p_{\text {Begg }}=0.013, p_{\text {Egger }}=0.042\right)$. Then, the trim and fill analysis were implemented, and the adjusted estimated effect was based on the random-effects model. The result in Figure 5 emerged that the adjusted values were consistent with the observed values (BMI: lower limit -0.164 to upper limit 0.354, Q = 0.592 ).

\section{Discussion}

A total of 13 studies were included to assess the impact of astaxanthin on cardiovascular disease in this meta-analysis. This report proved that astaxanthin had a significant influence on cardiovascular disease. The intake of astaxanthin significantly reduce the concentrations of total cholesterol, the concentrations of LDL-C, the concentrations of triglyceride, the concentrations of glucose and systolic blood pressure, and significantly increase the concentrations of HDL-C. In the study by Chen YQ et al, male spontaneously hypertensive rats (SHRs) were intragastric injected $200 \mathrm{mg} / \mathrm{kg}$ astaxanthin once a day, The untreated groups were gavaged with equivalent normal saline. After 11 weeks, SHRs suffered from gradually elevated blood pressure rising to 185/124 mmHg, the SBP and DBP of ATX-treated SHRs were reduced to 153/100 mmHg [35]. Kumar R et al. received $50 \mathrm{mg} / \mathrm{kg}$ astaxanthin orally with gavage and served as test group for astaxanthin, The total cholesterol in experimental group is significantly decreased compared to the control group, and HDL-C is significantly increased [21]. Meanwhile, the atherosclerotic lesions were significantly reduced compared with the control group [21]. The research findings by Birudaraju D, et al. showed that active group subjects (Contains astaxanthin) could improve the endothelial function and reduce SBP at 4 weeks [20].

Nevertheless, the previous meta-analysis didn't indicate a significant effect of astaxanthin supplementation on plasma lipid profile[10]. The reasons for inconsistency may be different retrieval times, different retrieval database or different sample size. In the sensitivity analysis, the effect size was relatively stable, and removing any individual study didn't affect the overall results. In HDL-C studies, the potential heterogeneity was statistically significant. However, sensitivity analysis indicated that there were no significant fluctuations. The main reasons are as followings: (1) Chen DF et al. only used women as subjects [17]; (2) The subjects were all men in the research by Guang Yang et al. [14]; (3) Two studies (Mashhadi NS,2018; Chen DF, 2015) didn't specify the daily dose of astaxanthin [5,14]. These factors partly affected the level of heterogeneity to a certain degree. Thus, excluding one study could reduce heterogeneity.

The molecular and cellular mechanisms of astaxanthin in cardiovascular disease are as follows $\mathbb{1} 1$. Since its chemical structure, astaxanthin has both polar region and nonpolar groups of the molecule, it takes on a transmembrane alignment on biofilms and protects cell membranes against RONS and oxidative damage; 2 . A series of conjugated bonds in the central non-polar region of astaxanthin makes the molecule to transport free radicals along its own carbon chain. Then removes them from the inside of the cell. finally, the free radicals are neutralized by other antioxidants located outside the cell membrane; 3. Astaxanthin neutralizes peroxynitrite, then inhibits lipid peroxidation and LDL oxidation; 4. Astaxanthin can reduces production of superoxide anion radicals released by NADPH oxidase and increases NO. Thus, astaxanthin appear to delay the progression of cardiovascular diseases [33]. Free radicals are highly reactive, which can trigger lipid peroxidation, destroy the primary groups and lead to genetic mutations. Then, they damage the sugar chains of cell membrane and cause the cell autolysis, change protein conformation and cause protein function loss. Finally, normal physiological activities are affected [18]. Astaxanthin has a role of antioxidant activities by quenching singlet oxygen and scavenging radicals to terminate chain reactions [19]. Therefore, This meta-analysis reconfirms the conclusion that astaxanthin has a protective effect on the cardiovascular system. Moreover, no serious adverse effects of astaxanthin consumption have been reported in animals and humans, even at the high dose of $45 \mathrm{mg} / \mathrm{d}$ [15,22,25,26,27]. These results support the safety of astaxanthin for future clinical studies.

\section{Study strengths and limitations}

Similar to all studies, several limitations existed in this meta-analysis. Firstly, the included studies and sample size is smaller (a total of 13 included articles with 694 cases). When the number of the studies is smaller than 10 in analysis, the power of the publication bias test is declined, and the combined results are unstable [16]. Secondly, the confounding factors should be adjusted, including age, sex, environmental factors, lifestyle and the dose of medicine. To move forward in the research project of astaxanthin on the cardiovascular system, the literature will be collected and the data will be updated in time in the future. The animal experiments will be conducted to analyze the effect of astaxanthin on the cardiovascular system.

\section{Conclusion}

This is a meta-analysis to comprehensively assess the effect of astaxanthin on the risk of cardiovascular disease. The study is an update on previous research reports. The results showed that astaxanthin could significantly reduce the concentration of blood sugar, concentration of blood lipid and blood pressure, and the analysis suggested that astaxanthin supplementation plays an essential role in preventing cardiovascular disease. In summary, the updated literature analysis in this study further verified that astaxanthin had a protective effect on cardiovascular system. 


\section{Declarations}

\section{Acknowledgments}

Authors particularly thank the Department of Biology at Hainan Medical University for its kind helps.

\section{Authors' contributions}

GXZ and DL designed the study and revised the manuscript. LZ, KRR, MRL, HR and QPY searched the literature, MWY and YHQ analyzed the data and summarized the results. All authors passed on the final version of the manuscript.

\section{Funding}

This research was supported by Hainan Provincial Natural Science Foundation of China (grant numbers: 821RC577, 821QN0897 and 820RC632), Scientific Research Project of Hainan Colleges and Universities (grant numbers: Hnky2020-34) and Open project of Hainan Provincial Key Laboratory of Basic Medicine (grant numbers: JCKF2020002). Availability of data and materials

All data generated or analyzed during this study are included in this published article.

\section{Ethics approval and consent to participate}

Not applicable.

\section{Consent for publication}

Not applicable.

\section{Competing interests}

The authors have declared that they have no competing interests. This meta-analysis was written independently.

\section{Author details}

${ }^{1}$ First school of clinical medicine, Hainan Medical University, Haikou, Hainan, China.

${ }^{2}$ School of Basic Medical and Life Science, Hainan Medical University, Haikou, Hainan, China.

${ }^{3}$ Second Clinical Medical College, Hainan Medical University, Haikou, Hainan, China.

${ }^{4}$ Research Center for Drug Safety Evaluation of Hainan Province, Hainan Medical University, Haikou, Hainan, China.

\section{References}

1. Zhu XL,Qiu H.Distribution and source of astaxanthin. Hunan Feed, 2008, (3): 35-37,12.

2. Fakhri S,AbbaszadehF, Dargahi L, et al. Astaxanthin: A mechanistic review on its biological activities and health benefits[J]. Pharmacol Research, 2018, 136: 1-20.

3. Ambati RR, PhangSM, Ravi S,et al. Astaxanthin: sources, extraction, stability, biological activities and its commercial applications-A review[J]. Marine Drugs,2014,12(1):128-52.

4. Fakhri S,Aneva IY, Farzaei MH, et al. The Neuroprotective Effects of Astaxanthin: Therapeutic Targets and Clinical Perspective[J]. Molecules, 2019, 24(14):2640.

5. Marazzi G, Pelliccia F, Campolongo G, et al. Usefulness of Nutraceuticals (Armolipid Plus) Versus Ezetimibe and Combination in StatinIntolerant Patients With Dyslipidemia With Coronary Heart Disease[J].The American Journal of Cardiology,2015,116(12):1798-1801.

6. Ruscica M, Gomaraschi M,Mombelli G, et al. Nutraceutical approach to moderate cardiometabolic risk: Results of a randomized, doubleblind and crossover study with Armolipid Plus[J]. Journal of Clinical Lipidology, 2014, 8(1):61-68. 
7. Chen DF, Wang HY,Zhang CT, et al. Study on the function of astaxanthin capsule in lowering blood lipid in hyperlipidemia[J].Henan J Prev Med, 2015, 22(012):1435-1437.

8. Choi HD,YounYK, ShinWG. Positive Effects of Astaxanthin on Lipid Profiles and Oxidative Stress in Overweight Subjects[J].Plant Foods Hum Nutr,2011,66(4):363-369.

9. Du L, Li J, Lei L, et al. High Vimentin Expression Predicts a Poor Prognosis and Progression in Colorectal Cancer:A Study with Meta-Analysis and TCGA Database[J].BioMed Research International, 2018(2018).

10. Sorin U, Amirhossein S, Maria-Corina S, et al. Lipid profile and glucose changes after supplementation with astaxanthin:a systematic review and meta-analysis of randomized controlled trials[J].Arch Med Sci,2015,11,(2): 253-266.

11. Yoshida $\mathrm{H}$,Yanai $\mathrm{H}$, Ito $\mathrm{K}$, et al. Availab Administration of natural astaxanthin increases serum HDL-cholesterol and adiponectin in subjects with mild hyperlipidemia[J]. Atherosclerosis, 2010, 209(2):520-523.

12. Mashhadi NS, Zakerkish M, Mohammadiasl J, et al. Astaxanthin improves glucose metabolism and reduces blood pressure in patients with type 2 diabetes mellitus[J]. Asia Pacific Journal of clinical nutrition,2018,27(2):341-346.

13. Chen JT, Kotani K. Effects of Astaxanthin on Liver and Leukocyte Parameters in Healthy Climacteric Women: Preliminary Data[J].2017,20(7):724-725.

14. Yang G, Wu LJ. Effects of Astaxanthin on Antioxidant Indexes and Serum Lipid Metabolites in Exercises[J],Contemporary Sports Technology,2015(10):14.

15. Peng L, Zhao P, Li B, et al. Antioxidant effects and impact on human health of astaxanthin[J]. Chinese Journal of Food Hygiene, 2011, 23(4):313-316.

16. Sterne JA, Gavaghan D, Egger, M. Publication and related bias in meta-analysis: power of statistical tests and prevalence in the literature[J].Journal of Clinical Epidemiology,2000,53(11):1119-1129.

17. Chen DF,Wang HY, Zhang CK, et al. Study on the 90 days Feeding test of Natural Astaxanthin in Rats[J]. Henan Journal of Preventive Medicine,2011,22(6):423-425,427.

18. Yao KF, Zhang RL, Liu XJ,et al. Studies on Anti-lipid Peroxidation Activity of Different Stereoisomeric Astaxanthin[J].Journal of Chinese Institute of Food Science and Technology,2018,18(10):86-94.

19. Fakhri S,Abbaszadeh F,Dargahi L,et al. Astaxanthin: A mechanistic review on its biological activities and health benefits[J]. Pharmacol Research,2018 (136):1-20.

20. Birudaraju D, Cherukuri L, Kinninger A, et al. A combined effect of Cavacurcumin, Eicosapentaenoic acid (Omega-3s), Astaxanthin and Gamma -linoleic acid (Omega-6) (CEAG) in healthy volunteers- a randomized, double-blind, placebo-controlled study[J]. Clin Nutr ESPEN. 2020,35:174-179.

21. Kumar R, Salwe KJ, Kumarappan M. Evaluation of Antioxidant, Hypolipidemic, and Antiatherogenic Property of Lycopene and Astaxanthin in Atherosclerosis-induced Rats[J]. Pharmacognosy Res. 2017, 9(2):161-167.

22. Zhu XB, Wu J, Yu LD,et al. Experimental Study on Antioxidant Function of Astaxanthin in Human Body[J].Science and technology information,2020,12:206-208,211.

23. Wu HJ,Niu HJ, Shao AW,et al. Astaxanthin as a Potential Neuroprotective Agent for Neurological Diseases[J]. Marine Drugs,2015, 13(9):5750-5766.

24. Landon R, Gueguen V, Petite H, et al. Impact of Astaxanthin on Diabetes Pathogenesis and Chronic Complications[J]. Mar Drugs, 2020, 18: 357.

25. Shi LL, Han C, Zhao JP, et al. The Value of Food Antigen-Specific IgE in Predicting The Risk of Food Allergy in Children with Atopic Dermatitis[J]. Food and Nutrition in China,2019,25(01):31-35.

26. Niu T, Zhou J, Wang F, et al. Safety assessment of astaxanthin from Haematococcus pluvialis: Acute toxicity, genotoxicity, distribution and repeat-dose toxicity studies in gestation mice[J]. Regulatory Toxicology and Pharmacology, 2020, 115: 104695.

27. Kajita M, Kato T, Yoshimoto T, et al. Study on the safety of high-dose administration of astaxanthin[J]. Folia Japonica de Ophthalmologica Clinica.2010, 3(4):365-370.

28. Michiyuki S,Kazuhiko Y,Wataru S,et al. Astaxanthin increases choroidal blood flow velocity[J]. Graefes Archive for Clinical \& Experimental Ophthalmology, 2012, 250:239-245.

29. Iwamoto T, Hosoda K, Hirano R,et al.Inhibition of Low-Density Lipoprotein Oxidation by Astaxanthin[J].Journal of Atherosclerosis and Thrombosis,2000,7:216-222.

30. Karppi J, Rissanen TH, Nyyssönen K, et al. Effects of astaxanthin supplementation on lipid peroxidation[J].International journal for vitamin and nutrition research,2007,77(1):3-11.

31. Kiyotaka N, Takehiro K, Taiki M, et al. Antioxidant effect of astaxanthin on phospholipid peroxidation in human erythrocytes[J]. British Journal of Nutrition,2011,105(11):1563-1571.

Page $7 / 15$ 
32. Macdermid JC, Vincent JI, Gan BS,et al.A blinded placebo-controlled randomized trial on the use of astaxanthin as an adjunct to splinting in the treatment of carpal tunnel syndrome[J]. Hand,2012,7(1):1-9

33. Pereira CPM, Souza ACR, Vasconcelos AR, et al. Antioxidant and anti-inflammatory mechanisms of action of astaxanthin in cardiovascular diseases (Review)[J]. Int J Mol Med. 2021,47(1):37-48.

34. Xue Y, Sun C, Hao Q, et al. Astaxanthin ameliorates cardiomyocyte apoptosis after coronary microembolization by inhibiting oxidative stress via Nrf2/HO-1 pathway in rats[J]. Naunyn Schmiedebergs Arch Pharmacol. 2019, 392(3):341-348.

35. Chen YQ, Li S, Guo YX, et al. Astaxanthin Attenuates Hypertensive Vascular Remodeling by Protecting Vascular Smooth Muscle Cells from Oxidative Stress-Induced Mitochondrial Dysfunction[J]. Oxid Med Cell Longev. 2020, 14;2020:4629189.

\section{Tables}

\section{Table 1}

the Characteristics of included studies. 


\begin{tabular}{|c|c|c|c|c|c|c|}
\hline First author, year & Country & Age & Sex(Male/Female) & $\begin{array}{l}\text { Astaxanthin dose } \\
\text { (mg/day) }\end{array}$ & Placebo dose (mg/day) & Follow-up (day) \\
\hline${ }^{8}$ Choi HD,2011 & Korea & $\begin{array}{l}20- \\
55\end{array}$ & $23 / 4$ & 20 & 20 & 84 \\
\hline${ }^{29}$ Iwamoto T,2000 & Japan & $\begin{array}{l}20- \\
36\end{array}$ & - & 1.8 & 0 & 14 \\
\hline${ }^{29}$ Iwamoto T,2000 & Japan & $\begin{array}{l}20- \\
36\end{array}$ & - & 3.6 & 0 & 14 \\
\hline${ }^{29}$ Iwamoto T,2000 & Japan & $20-$ & - & 14.4 & 0 & 14 \\
\hline${ }^{29}$ Iwamoto T,2000 & Japan & $\begin{array}{l}20- \\
36\end{array}$ & - & 21.6 & 0 & 14 \\
\hline${ }^{30}$ Karppi J,2007 & Finland & $\begin{array}{l}19- \\
33\end{array}$ & - & 8 & 8 & 90 \\
\hline${ }^{11}$ Yoshida H,2011 & Japan & $\begin{array}{l}20- \\
65\end{array}$ & $41 / 20$ & 18 & 0 & 84 \\
\hline${ }^{11}$ Yoshida H,2011 & Japan & $\begin{array}{l}20- \\
65\end{array}$ & $41 / 20$ & 12 & 0 & 84 \\
\hline${ }^{11}$ Yoshida H,2011 & Japan & $\begin{array}{l}20- \\
65\end{array}$ & $41 / 20$ & 6 & 0 & 84 \\
\hline${ }^{13}$ Chen JT,2016 & Japan & $\begin{array}{l}46- \\
56\end{array}$ & $0 / 29$ & 12 & 12 & 90 \\
\hline${ }^{12}$ Mashhadi NS,2018 & Iran & $\begin{array}{l}30- \\
60\end{array}$ & $17 / 27$ & - & - & 56 \\
\hline${ }^{14}$ Yang G,2015 & China & $\begin{array}{l}17- \\
23\end{array}$ & $16 / 0$ & 9 & 9 & 28 \\
\hline${ }^{7}$ Chen DF,2015 & China & $\begin{array}{l}38- \\
54\end{array}$ & $60 / 47$ & 3.72 & 0 & 45 \\
\hline${ }^{15}$ Peng L,2011 & China & $\begin{array}{l}45- \\
65\end{array}$ & $53 / 62$ & 40 & 0 & 90 \\
\hline${ }^{28}$ Michiyuki S,2012 & Japan & $\begin{array}{l}26- \\
50\end{array}$ & $5 / 15$ & 12 & 12 & 28 \\
\hline${ }^{31}$ Kiyotaka N,2011 & Japan & $\begin{array}{l}50- \\
63\end{array}$ & $10 / 10$ & 6 & 6 & 84 \\
\hline${ }^{31}$ Kiyotaka N,2011 & Japan & $\begin{array}{l}51- \\
62\end{array}$ & $10 / 10$ & 12 & 12 & 84 \\
\hline${ }^{22} \mathrm{Zhu}$ XB,2020 & China & $\begin{array}{l}37- \\
64\end{array}$ & $57 / 63$ & 9 & 9 & 90 \\
\hline $\begin{array}{l}{ }^{32} \text { Macdermid } \\
\text { JC,2012 }\end{array}$ & Canada & $\begin{array}{l}29- \\
74\end{array}$ & $18 / 45$ & 4 & 4 & 42 \\
\hline $\begin{array}{l}\text { 32 Macdermid } \\
\text { JC,2012 }\end{array}$ & Canada & $\begin{array}{l}29- \\
74\end{array}$ & $18 / 45$ & 4 & 4 & 84 \\
\hline
\end{tabular}

Table 2

The basis for Basis for heterogeneity and publication bias. 


\begin{tabular}{|lllllll|}
\hline & Point estimate (95\%Cl) & \multicolumn{2}{l}{ Heterogeneity } & \multicolumn{3}{c|}{ Publication bias } \\
& & $\mathrm{I}^{2}$ & $\mathbf{Q}$ & $\mathbf{P}$ & Begg & Egger \\
\hline Total cholesterol & $-0.310(-0.451,-0.168)$ & 0.000 & 13.598 & 0.755 & 0.00789 & 0.02386 \\
\hline HDL-C & $0.294(0.072,0.151)$ & 37.794 & 27.329 & 0.053 & 0.01401 & 0.08278 \\
\hline LDL-C & $-0.207(-0.396,-0.019)$ & 0.000 & 3.210 & 0.999 & 0.00240 & 0.00779 \\
\hline Triglyceride & $-0.603(-1.028,-0.179)$ & 84.083 & 87.956 & 0.000 & 0.06250 & 0.20944 \\
\hline Glucose & $-0.353(-0.596,-0.110)$ & 20.991 & 6.328 & 0.276 & 0.42549 & 0.24654 \\
\hline SBP & $-0.236(-0.425,-0.048)$ & 0.000 & 3.636 & 0.888 & 0.26581 & 0.21568 \\
\hline DBP & $-0.186(-0.374,0.002)$ & 0.000 & 1.235 & 0.996 & 0.10545 & 0.10254 \\
\hline BMI & $0.095(-0.164,0.354)$ & 0.000 & 0.592 & 0.999 & 0.01298 & 0.04178 \\
\hline
\end{tabular}

Table 3

Cochrane criteria as the evaluation criteria for the quality assessment.

Notice:" $\sqrt{ }$ " express the 'Low risk' of bias, " $X$ " as the 'High risk' of bias, "-" as the 'Unclear risk' of bias.

\begin{tabular}{|c|c|c|c|c|c|c|c|c|c|c|}
\hline & Selection bi & & $\begin{array}{l}\text { Performance } \\
\text { bias }\end{array}$ & $\begin{array}{l}\text { Detection } \\
\text { bias }\end{array}$ & $\begin{array}{l}\text { Attrition } \\
\text { bias }\end{array}$ & $\begin{array}{l}\text { Reporting } \\
\text { bias }\end{array}$ & $\begin{array}{l}\text { Other } \\
\text { bias }\end{array}$ & & & \\
\hline $\begin{array}{l}\text { First author! } \\
\text { year }\end{array}$ & $\begin{array}{l}\text { Random } \\
\text { sequence } \\
\text { generation }\end{array}$ & $\begin{array}{l}\text { Allocation } \\
\text { concealment }\end{array}$ & $\begin{array}{l}\text { Blinding of } \\
\text { participants } \\
\text { and } \\
\text { personnel }\end{array}$ & $\begin{array}{l}\text { Blinding of } \\
\text { outcome } \\
\text { assessment }\end{array}$ & $\begin{array}{l}\text { Incomplete } \\
\text { outcome } \\
\text { data }\end{array}$ & $\begin{array}{l}\text { Selective } \\
\text { reporting }\end{array}$ & $\begin{array}{l}\text { Other } \\
\text { sources } \\
\text { of bias }\end{array}$ & $\begin{array}{l}\text { Low } \\
\text { risk }\end{array}$ & $\begin{array}{l}\text { High } \\
\text { risk }\end{array}$ & $\begin{array}{l}\text { Unclear } \\
\text { risk }\end{array}$ \\
\hline $\begin{array}{l}{ }^{8} \mathrm{Choi} \\
\mathrm{HD}, 2011\end{array}$ & $\sqrt{ }$ & - & $\sqrt{ }$ & - & $\sqrt{ }$ & - & $\sqrt{ }$ & 4 & 0 & 3 \\
\hline $\begin{array}{l}{ }^{29} \text { Iwamoto } \\
\mathrm{T}, 2000\end{array}$ & - & - & - & - & - & - & $\sqrt{ }$ & 1 & 0 & 6 \\
\hline $\begin{array}{l}{ }^{30} \mathrm{Karppi}, 2007\end{array}$ & $\sqrt{ }$ & $\sqrt{ }$ & $\sqrt{ }$ & - & $\sqrt{ }$ & - & $\sqrt{ }$ & 5 & 0 & 2 \\
\hline $\begin{array}{l}{ }^{11} \text { Yoshida } \\
\text { H,2011 }\end{array}$ & $\sqrt{ }$ & - & $\sqrt{ }$ & - & $\sqrt{ }$ & - & $\sqrt{ }$ & 4 & 0 & 3 \\
\hline $\begin{array}{l}{ }^{13} \text { Chen } \\
\text { JT,2016 }\end{array}$ & $\sqrt{ }$ & - & $\sqrt{ }$ & - & - & - & $x$ & 2 & 1 & 4 \\
\hline $\begin{array}{l}\text { 12Mashhadi } \\
\text { NS,2018 }\end{array}$ & $\sqrt{ }$ & - & $\sqrt{ }$ & - & $\sqrt{ }$ & - & $\sqrt{ }$ & 4 & 0 & 3 \\
\hline $\begin{array}{l}\text { 14Yang } \\
\text { G,2015 }\end{array}$ & $\sqrt{ }$ & $\sqrt{ }$ & - & - & $\sqrt{ }$ & - & $\sqrt{ }$ & 4 & 0 & 3 \\
\hline $\begin{array}{l}{ }^{7} \text { Chen } \\
\text { DF,2015 }\end{array}$ & $x$ & $\sqrt{ }$ & $\sqrt{ }$ & - & $\sqrt{ }$ & - & $\sqrt{ }$ & 4 & 1 & 2 \\
\hline $\begin{array}{l}{ }^{15} \text { Peng } \\
\text { L,2011 }\end{array}$ & $\sqrt{ }$ & $\sqrt{ }$ & - & - & $\sqrt{ }$ & - & $\sqrt{ }$ & 3 & 0 & 4 \\
\hline $\begin{array}{l}{ }^{28} \text { Michiyuki } \\
\text { S,2012 }\end{array}$ & $\sqrt{ }$ & $\sqrt{ }$ & $\sqrt{ }$ & - & - & - & $\sqrt{ }$ & 4 & 0 & 3 \\
\hline $\begin{array}{l}{ }^{31} \text { Kiyotaka } \\
\text { N,2011 }\end{array}$ & $\sqrt{ }$ & $\sqrt{ }$ & $\sqrt{ }$ & - & - & - & $\sqrt{ }$ & 4 & 0 & 3 \\
\hline $\begin{array}{l}{ }^{22} \mathrm{Zhu} \\
\mathrm{XB}, 2020\end{array}$ & $\sqrt{ }$ & - & - & - & - & - & $\sqrt{ }$ & 2 & 0 & 5 \\
\hline $\begin{array}{l}\text { 32Macdermid } \\
\text { JC,2012 }\end{array}$ & $\sqrt{ }$ & $\sqrt{ }$ & $\sqrt{ }$ & $\sqrt{ }$ & - & - & $\sqrt{ }$ & 5 & 0 & 2 \\
\hline
\end{tabular}




\section{Figures}

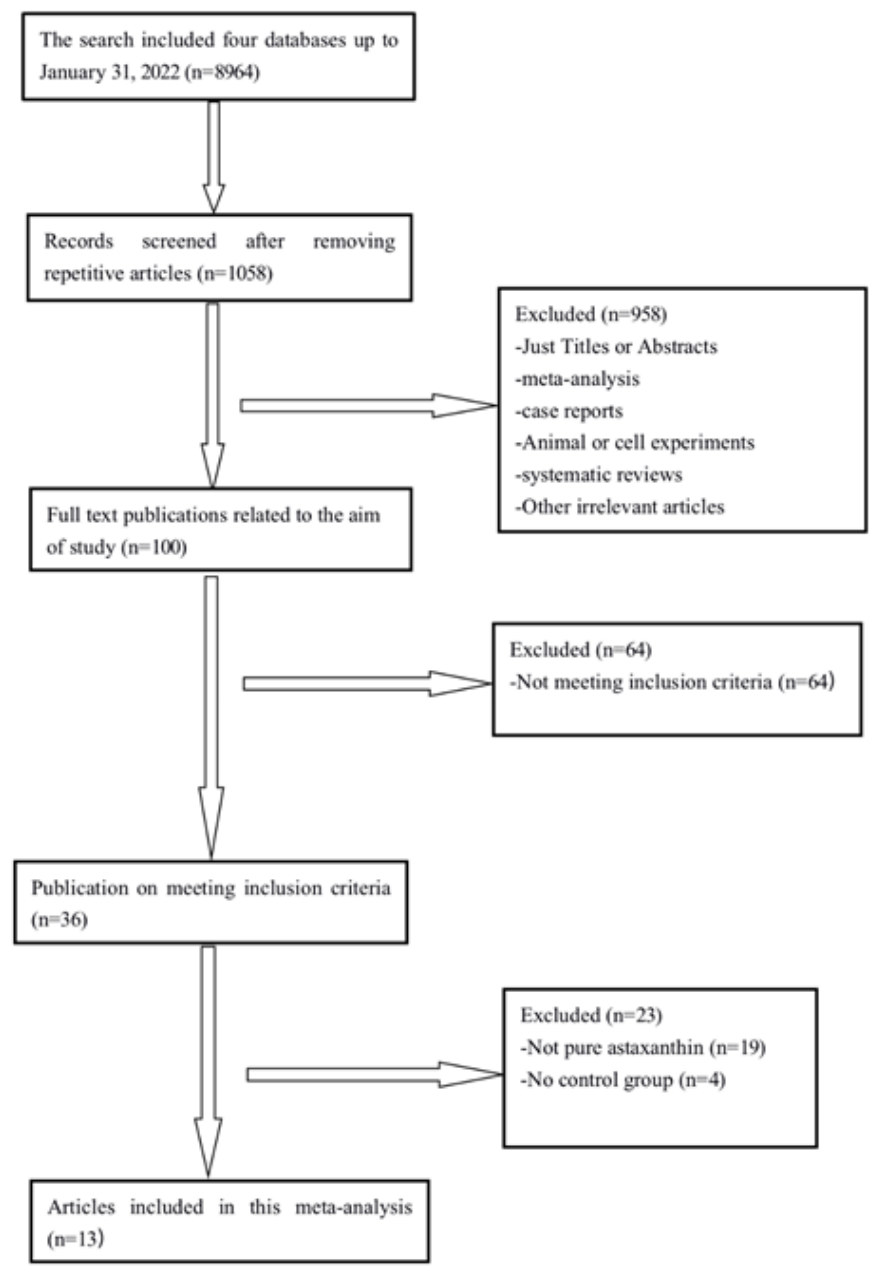

\section{Figure 1}

Flow diagram of the study selection procedure in this meta-analysis, which show the process of screening relevant studies based on the inclusion and exclusion criteria. 

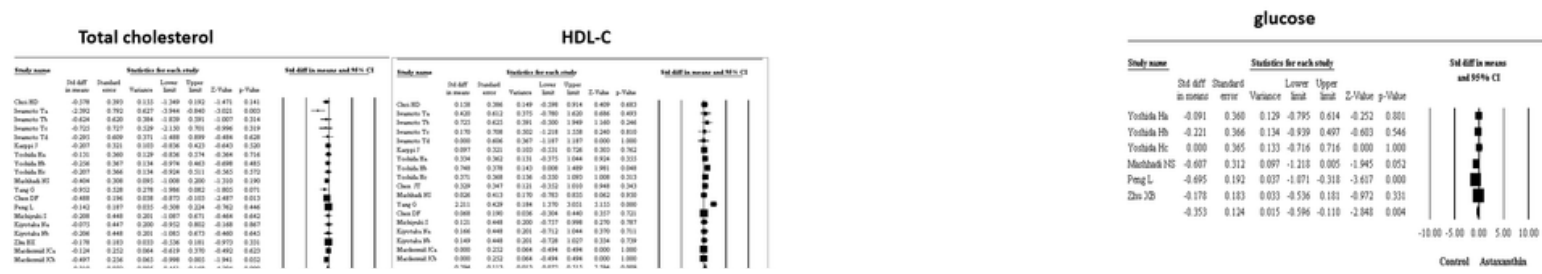

\section{Figure 2}

2.1. Forest plots detailing weighted mean difference (WMD) and $95 \%$ confidence intervals $(95 \% \mathrm{Cl})$ for the effect of astaxanthin on Blood lipid. The horizontal axis scale of the invalid line vertical line is 0.00 , and each horizontal line is the $95 \%$ confidence interval. The length of the horizontal line expresses the size of the confidence interval, The size of each box reflects the study's weight in the analysis. The $p$ value $<0.1$ indicated the existence of heterogeneity among studies.

2.2. Forest plots detailing weighted mean difference (WMD) and $95 \%$ confidence intervals $(95 \% \mathrm{Cl})$ for the effect of astaxanthin on glucose.

2.3. Forest plots detailing weighted mean difference (WMD) and $95 \%$ confidence intervals $(95 \% \mathrm{Cl})$ for the effect of astaxanthin on Blood pressure

2.4.Forest plots detailing weighted mean difference (WMD) and $95 \%$ confidence intervals $(95 \% \mathrm{Cl})$ for the effect of astaxanthin on $\mathrm{BMI}$ 


\section{Triglyceride}

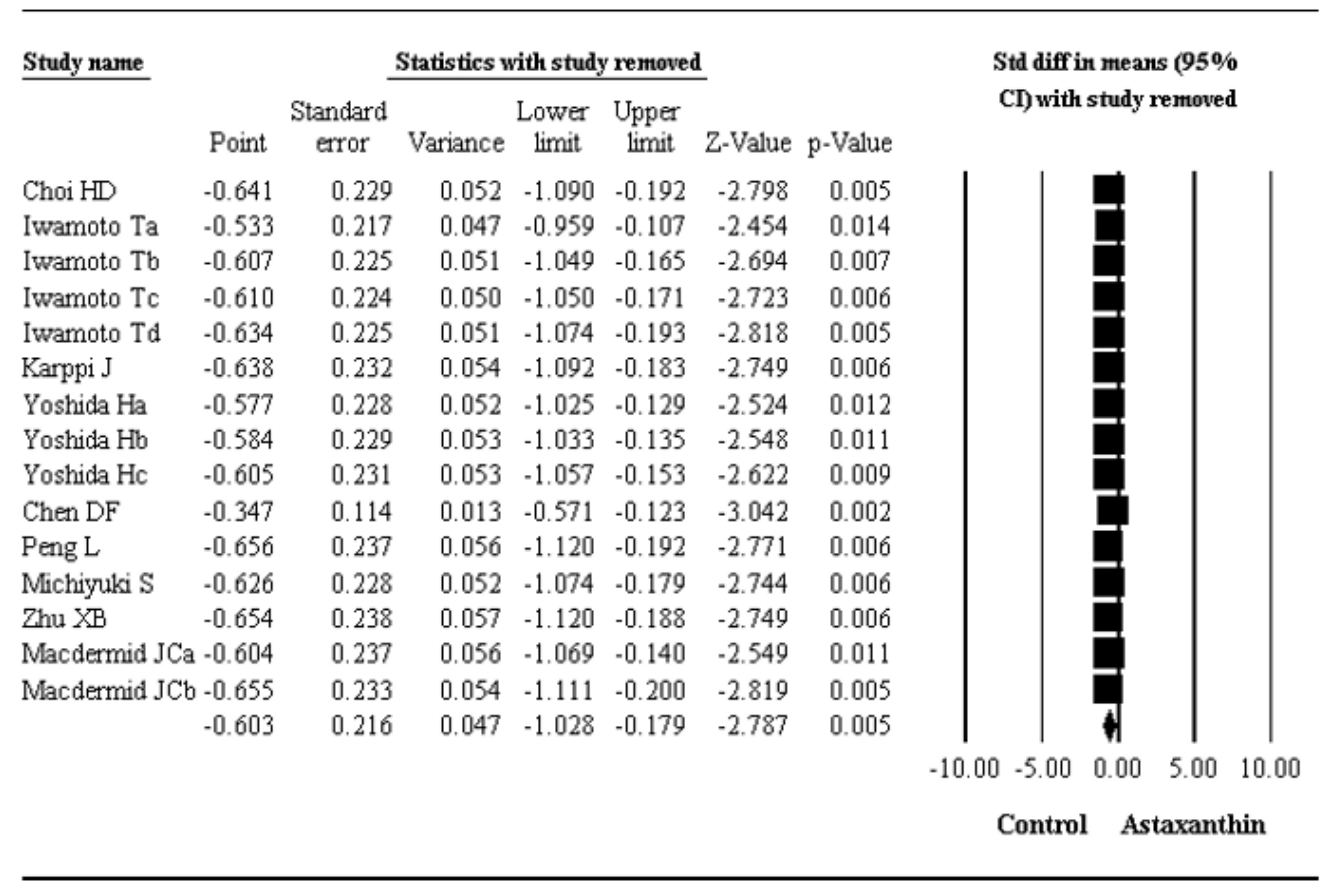

\section{Figure 3}

Sensitivity analysis was conducted using the one-study remove (leave-one-out) approach to evaluate the influence of each study on the overall effect size. 

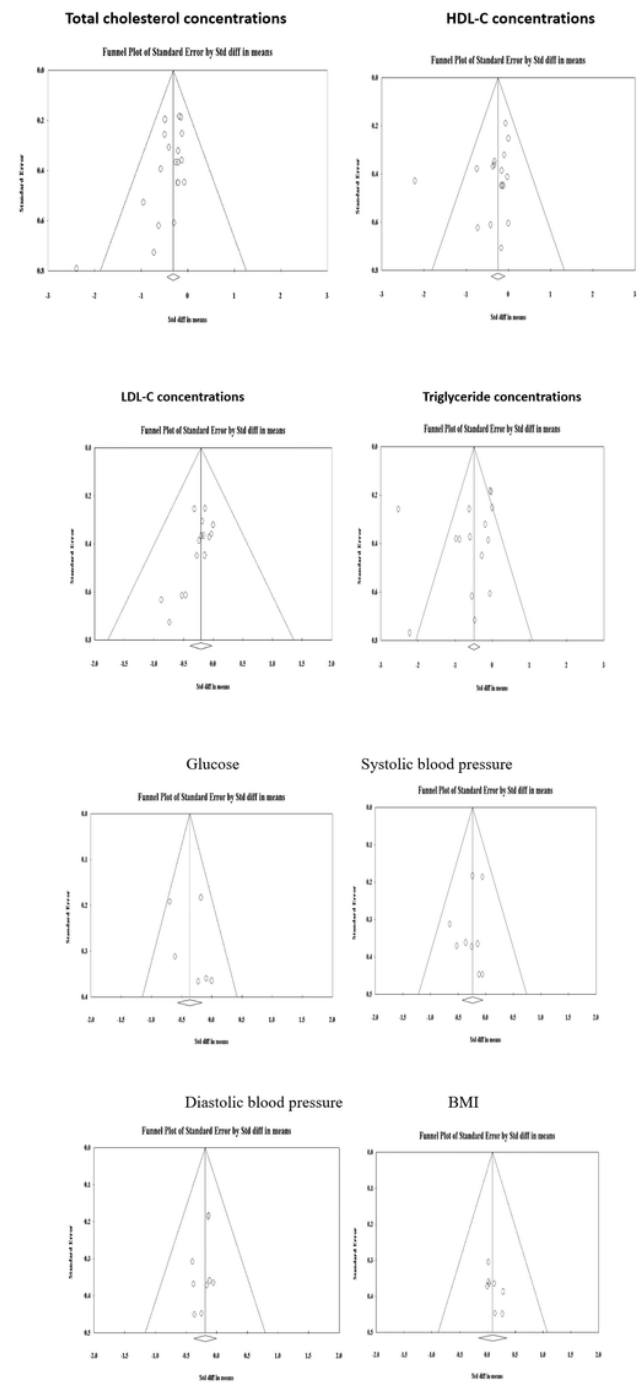

\section{Figure 4}

Funnel plots detailing publication bias about lipid profile in the studies selected for analysis. Circles represent observed published studies.


Figure 5 
Trim and fill method was used to impute for potentially missing studies and adjust the analysis for the effects of publication bias.

Page 15/15 